\title{
Dealing with sickness and incompetence: success and failure
}

\author{
Richard Smith
}

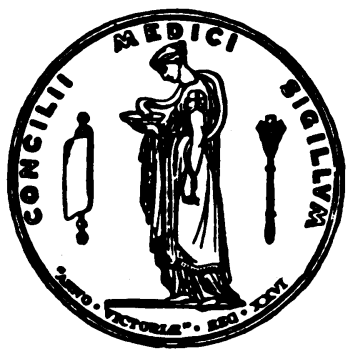

The General Medical Council's mechanism for dealing with sick doctors is widely perceived as one of its triumphs whereas its inability to tackle incompetence is one of its failures. The present president said on his appointment in November 1988 that the health committee "is one of the successes of the GMC and working well. Our 'cure' rate is about a third." And Jean Robinson, a lay member of the council and one of its sternest critics, says that the health committee "seems to work effectively and humanely." If the machinery has a deficiency it lies not in its effectiveness in dealing with doctors it encounters but rather in its failure to make contact with many of the sick doctors who are putting themselves and their patients at risk. Another defect may be that the council has no power over sick medical students despite evidence that sick doctors' problems commonly began when they were students.

The number of incompetent doctors is unknown, but the president of the GMC suggested to me that it may be of the order of $10-15 \%$ of independently practising doctors - that is, consultants or principals in general practice. Prevalences of $5 \%$ were bandied around at a closed meeting held a few years ago that included members of the defence societies. A Canadian study found "serious deficiencies" in the medical records or care of $8 \%$ of a random sample of 255 family practitioners and three of a sample of 136 specialists. ${ }^{4} \mathrm{~A}$ later study found that $15 \%$ of 649 family practitioners and $2 \%$ of 255 specialists from 11 disciplines had serious deficiencies (RG McAuley, congress on continu-

ing medical education, Los Angeles, 1988). The prevalence clearly depends critically on how incompetence is defined and measured, but few doctors dispute in private that incompetence is an important problem. At the moment the GMC can deal with incompetent doctors only through its disciplinary machinery, and the key question is whether there should be some other mechanism - as there is for sick doctors.

\section{Sickness among doctors}

Doctors are at excess risk for some physical illnesses, but generally their physical health is good-and their life expectancy is above that of the general population. ${ }^{5}$ Psychiatric illness presents the biggest threat to doctors, and rates of suicide, affective psychosis, and alcohol and drug dependence exceed those in the general population. ${ }^{6.9}$ The causes include stress and easy access to drugs, but also important is the fact that vulnerable people may opt for a career in medicineperhaps after being impressed by the help they have received during a breakdown. Such vulnerable people may have much to offer medicine, but their presence in the profession makes it especially important that there are mechanisms to help doctors who are sick and to protect their patients.

\section{Punishing the sick}

Before the Medical Act 1978 the GMC had no special

FIG 1-Health procedures of the General Medical Council
British Medical Journal, London WC1H 9JR

Richard Smith, MB, senior assistant editor

BrMed f 1989;298:1695-8

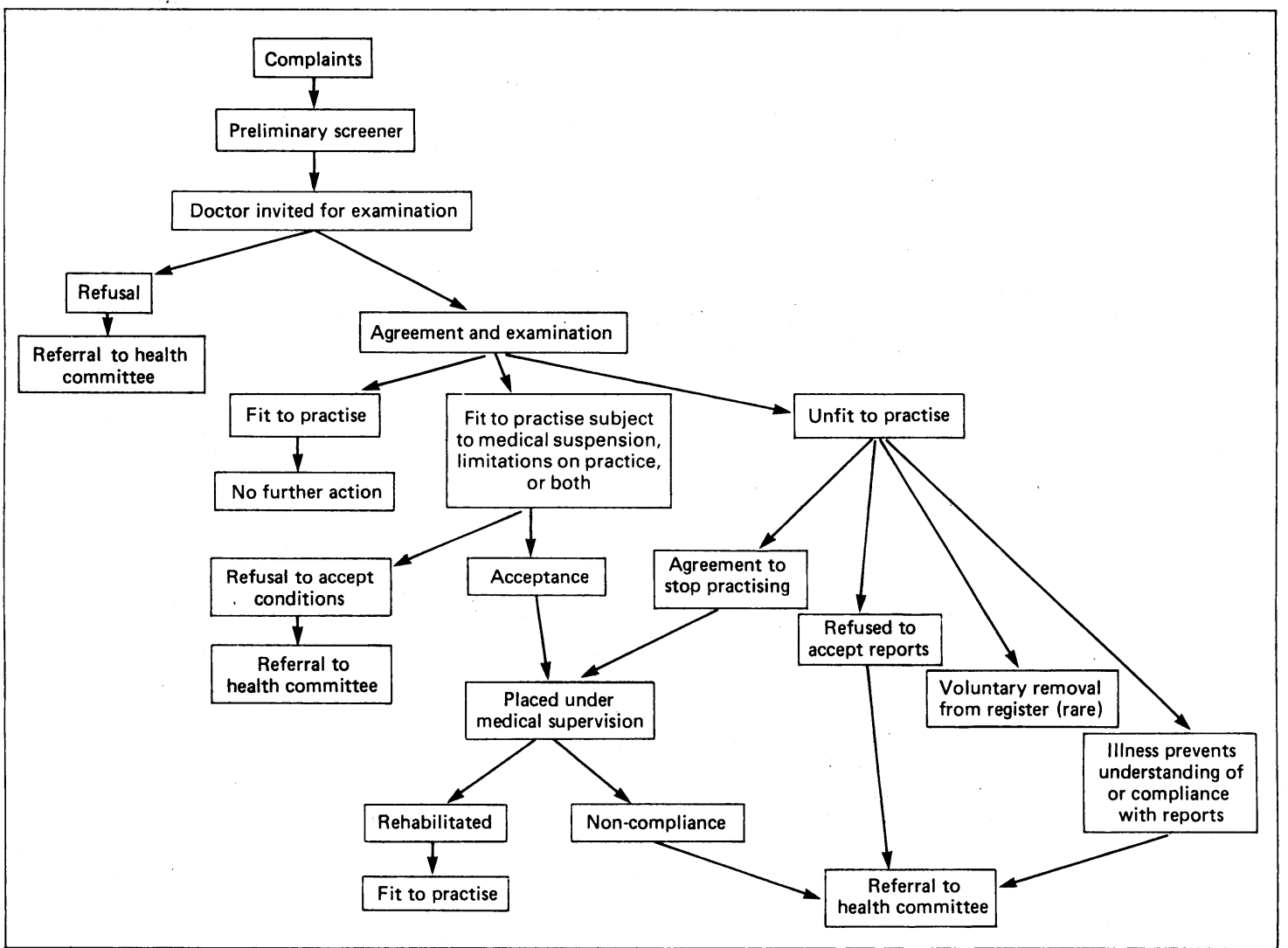




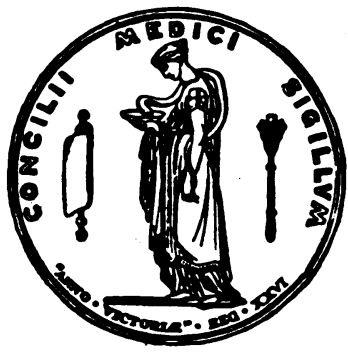

machinery for dealing with sick doctors, who could be dealt with only through disciplinary machinery and only after a complaint had been received. The Merrison commission examining this question and concluded: "The need for the GMC to have power to control the right to practise of the sick doctor is so overwhelming and so obvious that it seems to us amazing that the GMC has continued so long without such a power."10 Disturbingly, the Irish Medical and Dental Council (which split off from the GMC at independence) still does not have such a mechanism.

The commission heard of a "doctor who believed that his practice of a form of sexual perversion on patients was beneficial to their particular condition" and of doctors who had been known to be alcoholics for 20 years or more and yet had continued to practise. Other cases were presented to the commission (see box), and clearly the existing NHS machinery to help sick doctors was not working.

The machinery that existed then in the hospital service was the "three wise men" procedure; this still exists and operates locally. The three wise men are commonly the chairman of the medical advisory committee of a health district, the chairman of the hospital staff committee of the hospital in which the doctor works, and one other respected senior consultant. Cases are referred to them and they seek to examine the doctor and if necessary arrange treatment. They work secretly and by persuasion; they have no statutory power but simply advise the district manager, whose ultimate power is dismissal from the district. But the doctor might well seek employment elsewhere. Doctors who work continually as locums are long recognised as a group at high risk of both sickness and incompetence. General practice has similar machinery built around doctors appointed by the family practitioner committee and the local medical committee.

Nobody can be sure how well these procedures work because no records are kept and no data published. They are widely perceived, however, by those who are interested in the problem of sick doctors, as ineffective. The Merrison commission concluded that they were "insufficiently effective" and "not widely enough understood." The commission was also concerned by the lack of coordination in the NHS machinery and by the fact that the machinery clearly did not apply to doctors working in private practice. It was for these reasons that it opted for machinery within the GMC for dealing with sick doctors. Yet despite its criticisms of the NHS machinery the commission rejected evidence

\section{Cases of sick doctors presented to the Merrison inquiry}

Dr A was a locum who piled all the drugs in the surgery into a bucket, which he then put in the waiting room with a label asking patients to help themselves and not to bother him. When taxed with this behaviour by the GMC he said that his method of treatment was no more random than that of other doctors

Mr B was a surgeon who continued operating despite having a progressive disabling disease. He took part in two operations in which patients were seriously harmed

Dr C came to the GMC's notice because of a homosexual assault on a young boy. He was an alcoholic and seemed to be able to avoid homosexual behaviour if he abstained from alcohol. Erased from the register for his criminal act, he was later restored on evidence that he was being treated for his alcohol problems. When he lapsed the council could do nothing until he committed a further criminal offence.

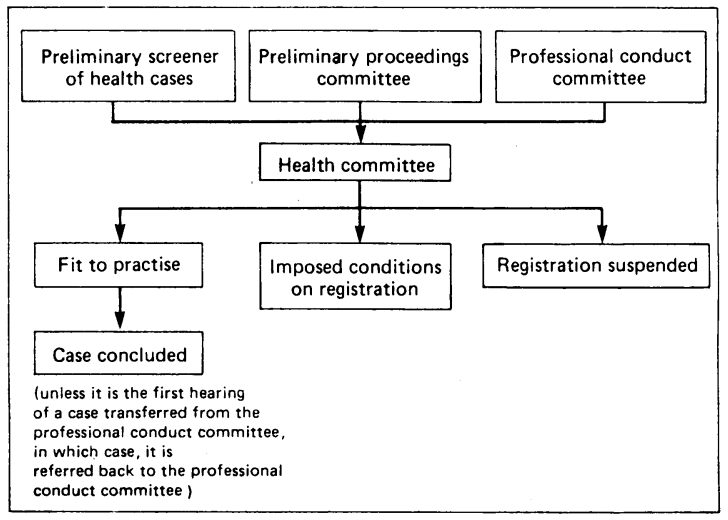

FIG 2-Work of the health committee

from the GMC that the council should operate its own local machinery. The commission recommended that central GMC machinery be built on that existing locally in the NHS. Its main argument was that local NHS machinery, unlike that in the GMC, could offer the practical assistance that sick doctors would need"such as the rearrangement of duties, the granting of sick leave, and help with remuneration and superannuation problems."

It has come to pass that the GMC's central machinery does rest on NHS local machinery-only not in a formal way. The intention is that local NHS machinery will deal with most cases and that the council will be invoked only for serious cases or when the local machinery has failed. But this organisational structure clearly raises questions about overall effectiveness: if the local machinery is defective, as has usually been concluded, the impact of the central machinery will be limited no matter how effective it might be in itself.

The NHS machinery has been improved since the Merrison commission produced its report. In 1982 the panel from which the three wise men are chosen was expanded to include one member of the senior dental staff of a district, a community physician, and a general practitioner with an appointment in the hospital where the doctor works. In addition, the royal colleges and the BMA have together set up a National Counselling Service for Sick Doctors, ${ }^{11}$ which has grown out of a service set up for anaesthetists by the Association of Anaesthetists of Great Britain and Ireland with the Royal College of Psychiatrists. ${ }^{12}$ It is an entirely confidential service, and doctors cannot be referred directly from it to the GMC.

Services designed to help sick doctors suffer from "Catch 22." Because most doctors with insight into their problems often arrange help for themselves the services set up by the various bodies are mostly concerned with those who lack such insight. And these doctors need either a carrot or a stick to be brought to treatment and kept there. The confidential services have the unexciting carrot of confidentiality but no stick: they thus have difficulty encouraging doctors to be treated and become well again. The GMC in contrast has a stick, but the stick and the body wielding it are so frightening that only a small minority of sick doctors come near it.

\section{First stages of the health procedure}

The GMC's central machinery for dealing with a sick doctor swings into action in response to a report from somebody anxious about a doctor's health. ${ }^{13}$ This may come from the local committee that has failed to contain the problem or directly from a member of the public or another doctor. Between August 1980 when the system began and October 1988 the council received reports on 383 doctors. Calls from doctors 


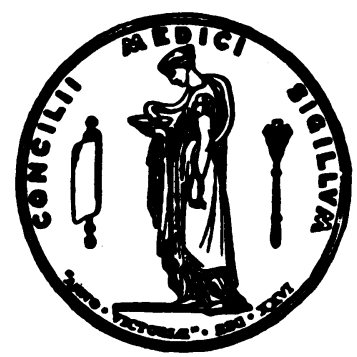

worried about colleagues may be diverted to the national counselling service if it seems that the council cannot help because the doctor's fitness to practise is not seriously impaired.

The report is considered first by the preliminary screener for health, who is at present Dr Philip Connell, a psychiatrist with a special interest in drug and alcohol problems. He looks for evidence that the doctor's fitness to practise may be impaired, and this is usually forthcoming if the report has come through the local machinery but may not be if the complaint comes from a patient or another doctor. The GMC's annual report for 1987 notes with disappointment that some doctors will contact the council about a colleague but are unwilling to supply enough evidence for it to act. ${ }^{14}$ In about a third of cases the screener does not pursue the case-either because the local machinery is controlling the problem or because there is not enough evidence that the doctor is seriously sick. The screener may sometimes attempt to gather more evidence, and occasionally the council's solicitors may be used.

If the screener is satisfied that there is enough evidence he invites the doctor to be examined by two independent consultants from a panel nominated by the royal colleges and professional organisations. This will usually be done locally, and most sick doctors looked after by the GMC are dealt with locally and never have to appear before the council. The local consultants will usually be psychiatrists but may be general physicians or neurologists, depending on the circumstances of the case. The sick doctor is also invited to submit reports from his or her general practitioner and consultants of his or her choice - who may perhaps have provided care previously. He or she has 28 days to decide whether to conform with this procedure, and the defence societies almost always advise compliance.

If the screener is satisfied from the reports of the examiners that the doctor's fitness to practise is seriously impaired by sickness he may then ask him or her $(86 \%$ of those investigated so far have been men $^{15}$ ) to agree to supervision and treatment from a nominated consultant. He or she may also be asked, according to the recommendations of the examiners, not to drink (about half of the cases entail alcohol (see table I)), not to take drugs unless prescribed, or to restrict his or her practice in some way. If the doctor agrees to this course he or she enters a "paper clinic" supervised by a deputy preliminary screener (at present a senior psychiatrist). At any time about 70 doctors are under suspension. In 1987, 26 doctors were added, and 14 were released because they were no longer putting patients at risk. Doctors who do not cooperate with this process are referred to the health committee.

Doctors who have been convicted of offences concerned with prescribing dangerous drugs (often prescribing them for themselves) or with drink driving offences may enter the council's health procedures from the preliminary proceedings committee.

\section{The health committee}

The health committee meets in private three times a year and has 12 members, one of whom is a lay member. It is elected each year, but the election system assures considerable continuity. The committee is popular because its work is more "medical" than that of the disciplinary committees. Also present at the hearings are two (sometimes three) medical assessors and a legal assessor. The council has tried hard to make the committee "user friendly"-and doctors are, for example, shown beforehand the room where the hearing will take place. The present chairman, Dr Tony Allibone, a general practitioner from Norfolk, would like to go even further with making the hearing less legalistic, but some members of the council think that the legal paraphernalia is unavoidable when a doctor's livelihood is at stake. The doctor appearing before the committee is sent all the evidence 28 days before the hearing, and he or she may bring a medical adviser, friend, member of the family, or a representative from the defence societies or a professional association. About two thirds are represented by their defence societies.

Unlike the cases heard by the professional conduct committee there is no prosecution case (except most rarely); the evidence against the doctor is presented on paper. The doctor may say what he or she wants, and then the medical advisers give their advice to the committee, which may then adjourn for more evidence, decide that the doctor is fit to practise (two cases out of the 60 heard since 1980), impose conditions on the doctor's practice, or suspend the doctor for a year or less (42 cases since 1980). Or if the doctor agrees the committee may impose conditions of treatment; if the doctor does not agree he or she could be suspended. The suspension has to be reviewed annually, and one amendment that the GMC wants to the medical act is the power to suspend some very sick (for example, brain damaged) doctors indefinitely to save them the misery of appearing regularly before the committee. Doctors can be encouraged to opt for voluntary erasure, but some do not have the insight to realise that this is the best course.

\section{Outcome and rehabilitation}

Figures 1 and 2 show what happens to the doctors entering the GMC's health procedure: roughly a third are not examined; another third are successfully rehabilitated; and the remainder are suspended, accept voluntary erasure, or die. The outcome figures are rough because at any one time many are going through the system.

Following the philosophy that sick doctors are to be helped rather than punished, the council is keen to develop mechanisms for their rehabilitation. It has had a series of meetings with regional medical officers attempting to establish sheltered posts for sick doctors returning to practise, which might also be used for doctors being rehabilitated after passing through the disciplinary process.

\section{Defects in the system}

Dr Allibone, chairman of the health committee, is generally pleased with the way that the health procedures work, but he has four particular worries. Firstly, doctors who appear before the committee are often financially impoverished: he would like to find ways to alleviate this-perhaps through medical charities. Secondly, impoverishment may be one reason why some doctors are not represented by their defence societies-because they cannot afford the subscriptions. Dr Allibone thinks that all doctors should have an opportunity to be represented. Thirdly, the relationship between the sick doctor and the medical supervisor appointed by the council may be complicated: sometimes the loyalties of the supervising doctor may be divided, and Dr Allibone thinks that perhaps there should be somebody between the doctor and the central GMC machinery-somebody like a probation officer, who can speak frankly to both sides in court. Fourthly, progress is not being made fast enough with the rehabilitation posts.

Dr Allibone also accepts that the GMC is probably dealing with only a small fraction of the sick doctors in Britain, and he is doubtful that the local machinery is coping adequately. Nobody knows how many doctors 
in Britain are sick, but a recent editorial in the $B M \mathcal{F}$ suggested that "a tenth of doctors may be impaired." This is necessarily a vague figure but might mean something like 10000 doctors, which means that the GMC-dealing with about 400 doctors in about 10 years -is hardly in touch with the problem. Dr Allibone would like to see the many bodies concerned with sick doctors sit down behind closed doors and take a hard look at the available data to monitor their effectiveness.

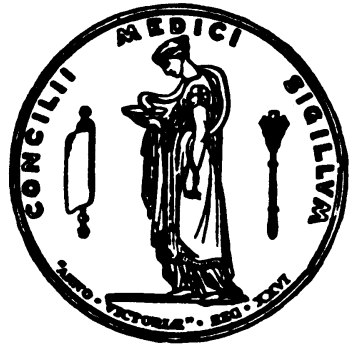

\section{On to incompetence}

One way to identify sick doctors would be to have more accurate data on their work performance. Experience from the United States shows that workplace programmes for helping people with alcohol problems begin to work effectively not when those "suspected of having alcohol problems" are fed into the system but rather when everybody whose work performance declines is asked why. ${ }^{16}$ Most doctors do not as yet have their work performance routinely monitored, but now that audit is becoming the order of the day this will change. ${ }^{17}{ }^{18}$ And measurement of poor work performance could feed not only into sickness procedures but also into systems for managing incompetence and improving performance.

The key question is how much the GMC should be part of these processes. Should there be a mechanism that feeds eventually from local audit into a GMC incompetence procedure? Some-including the present president of the council-think that if it played too prominent a part in the processes of audit doctors would be frightened away from audit itself. Most people would accept this, but at the same time-to protect the public-mechanisms may be needed to exercise power over doctors who perform badly and refuse to cooperate with educational measures designed to improve their performance. In other words, the council may need to be able to take action on what might be called "serious incompetence."

The council may already take action on certain cases of serious incompetence through its disciplinary procedures (17 June, p 1632), and it is under pressure to do more about cases of more minor incompetence through its disciplinary machinery. But the council's latest working party on disciplinary procedures, which has just reported, has resisted the pressure to create a lesser charge than serious professional misconduct, which might have been used as a method for dealing with incompetence. ${ }^{19}$ Rather it favours setting up "such competence procedures as seem appropriate," which will be done in cooperation with other medical bodies and patient organisations. The troubles with this development are that it seems to have come only after considerable pressure from outside and that it will happen only very slowly.

The royal colleges and health authorities are busy devising their own methods of audit, but one model that interests the GMC is the programmes run by the College of Physicians and Surgeons of Ontario. ${ }^{20}$ The physician review programme and the physician enhancement programme have four stages: a doctor's clinical competence is measured by standardised, objective tests (see box), and an "educational diagnosis" is reached; an "educational prescription" is devised; the individual "treatment" is given; and, finally, the doctor's performance is re-evaluated. Physicians whom the college think may be below standard are fed into this programme; others may choose to follow itat a cost of about $\$ C 2000$. The college also has a peer assessment programme, which in 1988 randomly assessed 160 family doctors and 150 general sugeons and paediatricians and found a "higher than expected rate of deficiency." ${ }^{21}$
Tests used by physician review programme of the College of Physicians and Surgeons of Ontario in assessing doctors' competence

- Practice management skills using medical records Doctors provide the assessors with a "practice profile." Specific records are then used to discuss history taking, diagnosis, management, and record keeping

- Data gathering and interpersonal skills using standardised patients

Doctors are presented with three standardised patients in an hour. Their consultations are viewed by two assessors through a two way mirror and videotaped for later discussion with the doctor. Each assessor and each patient evaluates the doctor separately

- Problem solving using structured oral examinations

- Assessment of clinical and procedural skills using an objective structured clinical examination

Standardised patients present the doctor with a well defined and common practice problem. The doctor must perform a specific clinical examination or procedure, interpret data, or give specific advice

- Assessment of knowledge through a multiple choice examination

\section{Conclusion}

The GMC's procedures for dealing with sick doctors work well but may engage with only a minority of sick doctors, which may be important because local mechanisms do not seem to be effective. A system of audit that routinely identified bad performance might be able to help doctors who are sick and those who fall below an accepted standard. The GMC is understandably reluctant to use its disciplinary mechanisms for responding to incompetence, but to satisfy public opinion it may need to move swiftly to encourage the development of local schemes for assessing competence-perhaps along the lines of the Canadian schemes. And it may well be necessary to have the power of the council at the back of the scheme-to deal with doctors who do not comply voluntarily.

1 Anonymous. New president for GMC. BrMed f 1988;297:1220.

2 Robinson J. A patient voice at the GMC. A lay member's view of the General Medical Council. London: Health Rights, 1988.

3 Murray RM. Characteristics and prognosis of alcoholic doctors. Br Med $\mathcal{f}$ 1976;ii:1537-9.

4 McAuley RG, Henderson HW. Results of the peer assessment program of the College of Physicians and Surgeons of Ontario. Can Med Assoc $\mathcal{F}$ 1984; 131:557-61.

5 Bennett G. The wound and the doctor: healing, technology and power in modern medicine. London: Secker and Warburg, 1987.

6 Pilowski L, O'Sullian G. Mental illness in doctors. Br Med f 1989;298:269-70.

7 Rucinski J, Cybulska E. Mentally ill doctors. Br f Hosp Med 1985;33:90-4.

8 Rucinski J, Cybulska E. Mentally ill doctors. Br $\mathcal{f}$ Hosp Med 1985;33:90-4. drugs: a 20 year follow up report. $N$ Engl f Med 1970;282:365-70.

drugs: a 20 year follow up report. $N$ Engl $\mathcal{F}$ Med 1970;282:365-70.
9 Murray RM. Psychiatric illness in male doctors and controls: an analysis of Murray RM. Psychiatric illness in male doctors and con
Scottish inpatient data. Brf Psychiatry 1977;131:1-10.

10 Committee of Inquiry into the Regulation of the Medical Profession. Report. London: HMSO, 1975. (Cmnd 6018.) (Merrison report.)

11 Rawnsley K. Helping the sick doctor: a new service. Br Med $\mathcal{f}$ 1985;291:922. 2 Anonymous. Do sick doctors need more than the GMC? Br Med F 1981;282: $1-2$.

13 Walton J. The Harben Lecture 1988. Illness in doctors and their families. Health and Hygiene 1989;10:51-62.

14 General Medical Council. Annual report 1987. London: GMC, 1988.

15 General Medical Council. Annual report 1988. London: GMC, 1989.

16 Smith R. Alcohol and work: a promising approach. Br Med F 1981;283: $1108-10$.

17 Secretaries of State for Health, Wales, Northern Ireland, and Scotland. Working for patients. London: HMSO, 1989. (Cmnd 555.)

8 Royal College of Physicians. Medical audit. London: RCP. 1989.

19 Working Party on the Council's Disciplinary Procedures in Response to Allegations of Failure to Provide a Good Standard of Medical Care. Report. London: GMC, 1989.

20 College of Physicians and Surgeons of Ontario. Professional evaluation and enhancement. Toronto: CPSO, 1988.

21 College of Physicians and Surgeons of Ontario. Peer assessment committee. Toronto: CPSO, 1988. 